\title{
Substitution of starch by soluble fiber and Saccharomyces cerevisiae dose response on nutrient digestion and blood metabolites for precision-fed dairy heifers ${ }^{1}$
}

\author{
G. J. Lascano, ${ }^{2}$ A. J. Heinrichs,${ }^{3}$ and J. M. Tricarico ${ }^{4}$ \\ Department of Dairy and Animal Science, The Pennsylvania State University, University Park 16802
}

\begin{abstract}
The objective of this experiment was to determine the effects of 2 levels of dietary starch and the dose at which the effects of yeast culture (YC) derived from Saccharomyces cerevisiae (Yea-Sacc ${ }^{1026}$, Alltech Inc., Nicholasville, KY) were maximized based on nutrient total-tract digestibility (AD), $\mathrm{N}$ utilization, and blood metabolites of precision-fed dairy heifers. A split-plot design with starch level as the whole plot and YC dose as subplot was administered in a 4-period (21 d), $4 \times$ 4 Latin square. Eight Holstein heifers (432.49 \pm 6.81 $\mathrm{kg}$ of body weight) were allocated to 2 starch treatments (28\% starch, high starch, HS, or $17 \%$ starch, low starch, LS) and to a sequence of $\mathrm{YC}$ doses $(0,10,30$, and $50 \mathrm{~g} / \mathrm{d})$. Dry matter $(\mathrm{DM})$ and neutral detergent fiber (NDF) AD were not different between $\mathrm{HS}$ and LS; however, HS decreased acid detergent fiber (ADF) and increased hemicellulose AD. Digestibility of DM and organic matter $(\mathrm{OM})$ increased quadratically in response to increasing YC dose. Hemicellulose, NDF, and $\mathrm{ADF} A D$ increased or tended to increase quadratically with increasing $\mathrm{YC}$ dose. No significant effects were noted on fecal or urine output between dietary starch concentrations; YC decreased wet and dry fecal output corresponding to the effect in DM and OM. Apparent $\mathrm{N}$ digestibility was greater in the LS group. As YC dose increased, fecal $\mathrm{N}$ output decreased quadratically and was lowest at $30 \mathrm{~g} / \mathrm{d}$ YC. A corresponding quadratic increase was observed for $\mathrm{N}$ retention expressed as a percentage of $\mathrm{N}$ digested: $\mathrm{N}$ output in urine tended to increase with increasing $\mathrm{YC}$ dose, resulting in no differences in retained $\mathrm{N}(\mathrm{g} / \mathrm{d})$. Dietary starch concentration
\end{abstract}

\footnotetext{
Received October 13, 2011.

Accepted January 30, 2012

${ }^{1}$ This research is a component of NC-1042; Management Systems to Improve the Economic and Environmental Sustainability of Dairy Enterprises.

${ }^{2}$ Current address: Department of Dairy Science, The California Polytechnic State University, San Luis Obispo 93407.

${ }^{3}$ Corresponding author: ajh@psu.edu

${ }^{4}$ Current address: Innovation Center for US Dairy, Rosemont, IL 60018.
}

did not affect blood glucose, triglyceride, creatinine, or lactate concentration. However, HS increased plasma urea $\mathrm{N}$ concentration. Glucose concentration tended to increase quadratically with daily $\mathrm{YC}$ dose in both starch treatments, with the greatest response at 30 $\mathrm{g} / \mathrm{d}$. For triglycerides, dietary starch concentration and YC dose interacted, decreasing quadratically in the LS group and increasing in the HS group (lowest and highest value for $10 \mathrm{~g} / \mathrm{d}$ respectively). We observed a significant time effect for all blood metabolites measured. We conclude that starch level did not affect DM $\mathrm{AD}$, but influenced ADF and hemicellulose AD. Yeast culture had the greatest effect on DM, NDF, ADF, and hemicellulose AD when added at $30 \mathrm{~g} / \mathrm{d}$. Addition of YC influenced glucose and triglyceride concentrations differently according to the dietary starch concentration of the diet.

Key words: heifers, starch, yeast culture, precision feeding

\section{INTRODUCTION}

Dairy heifer growth rates and body condition are often controlled by feeding high-fiber diets, which are often inefficient in terms of energy and protein utilization (Moody et al., 2007; Zanton and Heinrichs, 2007). This has attracted interest in the use of highly digestible and high-concentrate, precision-fed diets to improve feed utilization. Recently, the use of highconcentrate precision-fed diets has shown no negative effects on rumen fermentation (Lascano and Heinrichs, 2009; Lascano et al., 2009a), improved digestibility of $\mathrm{N}$ and $\mathrm{OM}$ (Zanton and Heinrichs, 2009), no difference in ammonia emissions to the environment (Lascano et al., 2008), and reduced manure output (Moody et al., 2007), and has resulted in similar milk yields when fed during different phases of the rearing period (Zanton and Heinrichs, 2010).

Controlling heifer DMI increases efficiency mainly because metabolic nutrient costs are higher when greater amounts of feed are consumed by ruminant animals (Hoffman et al., 2007). The tissues responsible for digestion, absorption, and intermediary metabolism 
must support intense oxidative metabolism, which determines the availability of nutrients remaining for maintenance, growth, and productive functions (Huntington and Reynolds, 1983). Negative effects of feeding rapidly fermented NSC have been observed in dairy cows, heifers, and calves when higher concentrate diets are fed (Nocek, 1997). However, starch can be replaced by alternative carbon sources for microbes, such as pectin and $\beta$-glucans, which are structural carbohydrates soluble in neutral detergent solution. Pectins are classified as a nonstarch polysaccharide fraction and referred to as neutral detergent-soluble fiber (NDSF), which also includes fructans and $\beta$-glucans (Van Soest, 1994). The main component of NDSF is pectin, and its fermentation generates relatively more acetate and less propionate and lactate than starch (Strobel and Russell, 1986; Leiva et al., 2000). Variation in composition among feedstuffs makes it possible to modify carbohydrate proportions in diets. Citrus pulp (CPP) is a valuable, high-energy by-product that can partly replace starch without having an adverse effect on milk yield or composition (Fegeros et al., 1995). However, rapid rates of degradation of dietary starch and sugars from CPP can result in low $\mathrm{pH}$ due to acid accumulation (Ariza et al., 2001). On the other hand, even though NDSF is also fermented rapidly in the rumen, it is not fermented to lactate and its fermentation ceases at low pH (Hall and Herejk, 2001).

The addition of yeast culture (YC) products based on Saccharomyces cerevisiae to the diet has resulted in improved productivity in both lactating and growing animals (Desnoyers et al., 2009). Although increases in productivity are generally variable, it seems that responses to $\mathrm{YC}$ addition involve rumen fermentation rate, patterns, and total-tract digestibility. Previous results have shown that DM, OM, and fiber digestibility were improved, ammonia concentrations reduced, and VFA concentrations and bacteria numbers increased when YC was added to diets of limit-fed dairy heifers (Dawson et al., 1990; Marden et al., 2008; Lascano et al., 2009b). The level of dietary YC recommended for heifers has been based primarily on lactating cow studies (Desnoyers et al., 2009) rather than studies using heifers of various ages. It has been suggested that research on dose response would help clarify the effects observed with YC addition in nonpregnant, nonlactating dairy cows (Wiedmeier et al., 1987). Because YC yielded similar responses in diets containing different forage to concentrate ratios in previous experiments (Lascano et al., 2009b; Lascano and Heinrichs, 2009), its effect might be related to nutrient sources supplied in the diet, rather than variation in forage to concentrate ratio. Studying an optimal dose of $\mathrm{YC}$ for the growing heifer could yield valuable information in terms of the potential for its inclusion in heifer diets. An additional objective was to investigate the effect on nutrient utilization in the dairy heifer when replacing NSC with NDSF.

\section{MATERIALS AND METHODS}

\section{Animals and Diets}

All procedures involving the use of animals were approved by the Pennsylvania State University Institutional Animal Care and Use Committee. Eight Holstein heifers $(432.49 \pm 6.81 \mathrm{~kg}$ of BW) fitted with 10-cm ruminal cannulas (Bar Diamond, Parma, ID) were randomly assigned to 2 starch treatments and to a sequence of doses of live $\mathrm{YC}(0,10,30$, and $50 \mathrm{~g} / \mathrm{d}$ of Yea-Sacc ${ }^{1026}$, Alltech Inc., Nicholasville, KY). Heifers were subjected to a split-plot, $4 \times 4$ Latin square design with 21-d periods. The whole-plot factor was dietary starch concentration and the subplot was YC dose. All diets were provided as TMR at a level calculated to provide equal intakes of ME and to allow for $800 \mathrm{~g} / \mathrm{d}$ of ADG. Dietary starch concentrations were approximately $30 \%$ for high starch (HS) and 15\% for low starch (LS), and diets were formulated to provide equal amounts of ME and CP (Table 1). These starch levels are used commonly on farm and allowed the use of a heavy corn diet as one treatment and a heavy by-product diet as the other. The $50 \%$ forage portion was provided by $35 \%$ corn silage and $15 \%$ grass hay, and the $50 \%$ grain portion consisted of a variety of byproducts and grains. Rations were balanced according to National Research Council (2001) standards.

Intake of $\mathrm{CP}$, dietary fiber ( $\mathrm{NDF}$ and $\mathrm{ADF}$ ), minerals, and vitamins was held constant across all diets, but dietary starch was allowed to vary with the ingredients composing the treatment rations by replacing ground corn and soybean hulls with CPP. Rations were mixed daily before feeding at $1200 \mathrm{~h}$, and the corresponding YC dose was top-dressed. Refusals (if present) and feed samples were collected daily during sample collection periods immediately before feeding. Heifers were housed in a ventilated, environmentally controlled tie-stall barn with rubber mattress bedding, and were allowed access to an exercise lot for $2 \mathrm{~h}$ before feeding on days on which sampling was not occurring. Heifers were weighed on $\mathrm{d} 0,1,7$, and 8 of each period, and the amount of feed offered for the following interval was based on the average of the previous 2 BW. Ad libitum access to water was monitored daily using volume water flow meters (Sensus Metering Systems, Uniontown, $\mathrm{PA})$. 
Table 1. Ingredient and nutrient composition of high (HS) or low (LS) starch diets fed to Holstein dairy heifers

\begin{tabular}{lrr}
\hline & \multicolumn{2}{c}{ Treatment } \\
\cline { 2 - 3 } Item & \multicolumn{2}{c}{ LS } \\
\hline Ingredient, \% of DM & \\
Corn silage & \\
Grass hay & 35.00 & 35.00 \\
Ground corn & 15.00 & 15.00 \\
Citrus pulp & 0.00 & 17.35 \\
Dry distillers grains & 28.95 & 0.00 \\
Soybean hulls & 19.05 & 22.65 \\
Mineral mix & 0.00 & 8.00 \\
Chemical composition ${ }^{3}$ & 2.00 & 2.00 \\
DM, \% & & \\
OM, \% of DM & 56.35 & 58.48 \\
CP, \% of DM & 94.58 & 94.99 \\
Ash, \% of DM & 13.78 & 13.84 \\
NDF, \% of DM & 5.03 & 4.50 \\
ADF, \% of DM & 38.37 & 37.55 \\
ADL, \% of DM & 23.24 & 20.81 \\
Hemicellulose, $\%$ of DM & 7.24 & 6.64 \\
Cellulose, \% of DM & 15.23 & 17.15 \\
Lignin, \% of DM & 16.32 & 15.00 \\
Starch, \% of DM & 6.87 & 6.22 \\
Ether extract, \% of DM & 16.74 & 27.92 \\
NFC, \% of DM & 5.30 & 5.87 \\
ME, Mcal/kg & 37.16 & 36.78 \\
Ca, \% of DM & 2.37 & 2.38 \\
P, \% of DM & 0.73 & 0.47 \\
Na, \% of DM & 0.33 & 0.33 \\
K, \% of DM & 0.12 & 0.13 \\
Mg, \% of DM & 1.10 & 1.15 \\
S, \% of DM & 0.21 & 0.22 \\
\hline Cont & 0.40 & 0.41 \\
\hline
\end{tabular}

${ }^{1}$ Contained $37.2 \%$ DM, 34.6\% NDF, 20.9\% ADF, $10.3 \%$ CP, $34.4 \%$ starch; DM basis.

${ }^{2}$ Contained $7.8 \%$ vitamin E, $2.6 \%$ vitamin ADE, $28.6 \%$ distillers corn with soluble vitamin D, $14.6 \%$ plain salt, $36.5 \%$ limestone, $2.6 \%$ magnesium oxide, $5.7 \%$ trace mineral premix, and $1.6 \%$ selenium premix; DM basis.

${ }^{3} \mathrm{n}=8$ composite samples representing 24 samples per treatment ration taken daily throughout the collection periods of the experiment. All ingredients and nutrients expressed on a DM basis unless otherwise specified.

${ }^{4}$ Hemicellulose $=$ NDF - ADF .

${ }^{5}$ Cellulose $=\mathrm{ADF}-\mathrm{ADL}$.

${ }^{6}$ Calculated from ingredients: $\mathrm{NFC}=100-(\mathrm{NDF}+\mathrm{CP}+$ ether extract + ash).

${ }^{7}$ Estimated: $\mathrm{ME}=\mathrm{TDN} \times 0.04409 \times 0.82$.

\section{Sample Collection and Analysis}

Adaptation to treatment rations was made over the first $15 \mathrm{~d}$ of each period followed by $6 \mathrm{~d}$ of sampling. Total collection of feces and urine was conducted from d 17 to 21 (4 d of total collection). Urine was collected via a modified urine device (Lascano et al., 2010), weighed, and subsampled $(250 \mathrm{~mL})$ daily just before feeding. Urine was acidified with $12 \mathrm{~N} \mathrm{HCl}$ as required to maintain $\mathrm{pH}$ below 3 to minimize $\mathrm{NH}_{3}-\mathrm{N}$ volatilization. Feces were collected hourly and stored in airtight containers. Every $24 \mathrm{~h}$, total collection of feces was weighed, mixed, recorded, and subsampled; samples were composited at the end of each collection period and dried or frozen at $-20^{\circ} \mathrm{C}$ for further analysis.

Forage and TMR samples were collected daily and composited (dry) every period; concentrate samples were collected once per period. Feed and fecal samples were dried in a forced-air oven $\left(55^{\circ} \mathrm{C}\right)$ for $72 \mathrm{~h}$, ground through a 1-mm screen using a Wiley mill (Arthur H. Thomas, Philadelphia, PA), and analyzed for DM, OM, ash (AOAC, 2000), ADF, NDF, and ADL (Van Soest et al., 1991) using an Ankom ${ }^{200}$ Fiber Analyzer (Ankom Technology Corp., Fairport, NY) with heatstable $\alpha$-amylase and sodium sulfite used for the NDF procedure. Cellulose and hemicellulose were determined by subtracting NDF from $\mathrm{ADF}$ and $\mathrm{ADF}$ from ADL, respectively. Starch was analyzed on samples reground to pass through a $0.5-\mathrm{mm}$ screen (Zanton and Heinrichs, 2009). Dried feed and wet fecal and urine samples were analyzed for $\mathrm{N}$ using the Kjeldahl method (AOAC, 2000). Urine was also analyzed for uric acid (uric acid kit 1051, Stanbio Laboratory Inc., San Antonio, TX), allantoin (Chen, 1989), and creatinine (procedure no. 0400; Stanbio Laboratory Inc.). Metabolizable energy intake was calculated for each heifer within each period using the observed digestible $\mathrm{OM}$ intake $\times 4.409 \times 0.82$ (NRC, 2001). On d 20 of each period, blood samples were taken $2 \mathrm{~h}$ before and after feeding. Blood was collected from the coccygeal vein into 10-mL evacuated serum tubes (Becton Dickinson Vacutainer Systems, Franklin Lakes, NJ) containing clot activator and into evacuated plasma tubes (Becton Dickinson Vacutainer Systems) containing $\mathrm{K}_{3}$ EDTA. All tubes were centrifuged at $1,300 \times g$ at $4^{\circ} \mathrm{C}$ for 10 min to obtain serum and plasma, which were aliquoted and stored at $-20^{\circ} \mathrm{C}$ until further analysis. Plasma was aspirated and stored at $-20^{\circ} \mathrm{C}$ until analysis for urea- $\mathrm{N}$ (procedure no. 0580; Stanbio Laboratory Inc.), glucose (procedure no. 1075; Stanbio Laboratory Inc.), and lactate (Liqui-UV test, procedure no. 2920, Stanbio Laboratory Inc.). Serum samples were used to determine concentrations of triglycerides (Stanbio Triglyceride LiquiColor Procedure No. 2200, Stanbio Laboratory Inc.) and creatinine (procedure no. 0400; Stanbio Laboratory Inc.)

\section{Statistical Analysis}

All statistical analyses were conducted in SAS (version 9.2, SAS Institute Inc., Cary, NC) using the MIXED procedure. Dependent variables were analyzed as a split-plot, $4 \times 4$ Latin square design with starch level as the whole plot and YC dose as the subplot. Animals had an adaptation period of $15 \mathrm{~d}$, even though in previous research a carryover effect was not observed when animals were adapted to new doses or new directfed microbial agents for $10 \mathrm{~d}$ (Nocek et al., 2002). For 
measurements repeated within a day, time and fixed effect interactions with time were included as repeated effects, and heifer was included as a random effect. All denominator degrees of freedom for $F$-tests were calculated according to Kenward and Roger (1997), and repeated measurements were analyzed including the first autoregressive covariance structure based on the low values received for goodness of fit measures, and Schwarz's Bayesian criterion. Heifer within starch level was used as the error associated with the whole-plot error, and the effect of starch assessed with the denominator degrees of freedom, whereas the effect of YC dose and the interaction were assessed against the pooled residual error. Normality of residuals was evaluated by using the Shapiro-Wilk test for normality. Differential responses between starch levels to YC were assessed for some variables through mixed model regression analysis; output from this analysis is displayed in figures as the adjusted (for random effect of heifer) response against YC dose. Some variables were analyzed using a mixed regression procedure for the different responses between dietary starch concentration to YC dose. Least squares means are presented in tables; statistical significance was declared at $P \leq 0.05$ and tendencies at $P \leq 0.10$ for main effects. Interactions were declared significant at $P \leq 0.10$.

\section{RESULTS AND DISCUSSION}

\section{Nutrient Intakes}

Dietary ingredient and chemical composition are presented in Table 1. Diets were formulated to differ mainly in starch level and contained 16.7 and $27.9 \%$ starch on a DM basis for LS and HS, respectively. To achieve this, CPP replaced all the corn and soybean hulls and part of the dry distillers grains in the LS diet. All other nutrients were formulated to be similar among treatments.

Nutrient intakes are presented in Table 2. The ADG of heifers was greater than forecast during the preliminary adaptation period; therefore, the amount of DM offered was reduced during the study to achieve targeted ADG. Because heifers were precision-fed, we expected to have similar nutrient intakes across diets except for starch, which was purposely formulated to be different, and nutrients that changed as a result of replacement of corn with CPP (i.e., ash, ADF, ADL, hemicellulose, lignin, and ether extract). Notwithstanding the reduction in DM offered, refusals were recorded for some heifers during the study, which likely accounted for the small but significant differences in DM and OM intakes between the LS and HS diets. Calculated intake of NFC was slightly but significantly greater for LS-fed than for HS-fed heifers and could be attributed to a greater concentration of organic acids (Leiva et al., 2000) and sugar (Bampidis and Robinson, 2006) in CPP than in corn. Heifers were fed diets formulated to provide 2.37 and $2.38 \mathrm{Mcal}$ of $\mathrm{ME} / \mathrm{kg}$ for LS and HS, respectively, and although DMI was lower for HS-fed than for LS-fed heifers (7.22 vs. $7.39 \mathrm{~kg} / \mathrm{d}$ ), rate of gain and ME intake $\left(0.18 \pm 0.01 \mathrm{Mcal} / \mathrm{kg}\right.$ of $\left.\mathrm{BW}^{0.75}\right)$ were not different between the 2 groups.

\section{Diet Digestibility}

Total-tract nutrient $\mathrm{AD}$ are presented in Table 3 . Dietary starch level did not affect $\mathrm{AD}$ of DM, OM, NDF, ash, or starch. However, greater starch reduced ADF $(P=0.02)$ and cellulose $(P \leq 0.01)$ and tended to increase hemicellulose $(P=0.07)$ AD. Bueno et al. (2002) reported a quadratic effect with increasing CPP concentration $(0,33,66$, and $100 \%)$ in the diet, with the highest $\mathrm{OM} \mathrm{AD}$ at $47.3 \% \mathrm{CPP}$ inclusion, but when CPP replaced all the corn available in the diet (0 vs. $100 \%$ CPP), no differences in OM and DM AD were observed (Bueno et al., 2002). They suggested that the combination of corn and CPP with different fermentability rates enhanced DM and OM digestibility. Forage NDF concentration was similar $(60.4 \pm 1.3 \%)$ between starch treatments in the present experiment, indicating that the variation observed in degradation of fiber components among starch treatments was based on the concentrate ingredients used to balance the rations. According to Miron et al. (2002), NDF digestibility increases when CPP replaces corn. However, NDF digestibility was not different between the HS and LS diets in the present experiment. These results could be explained by the inclusion in the HS diet of soybean hulls, which have a higher NDF digestion rate than CPP (Hall and Herejk, 2001) and higher hemicellulose (NDF - ADF) digestibility (Sarwar et al., 1991). Totaltract AD of ADF was lower in HS- than LS-fed heifers as a result of a reduction in cellulose (ADF - ADL) digestion, but $\mathrm{AD}$ of hemicellulose was similar in both treatments.

Starch digestibility of both diets was high (between 86 and $97 \%$; Table 3) and comparable to that observed in other studies using highly fermentable carbohydrates (Titgemeyer et al., 1992; Ariza et al., 2001). Sources of starch changed as starch concentration was manipulated in the diet; thus, 86 and $45 \%$ of starch was provided by corn silage for the LS and HS diets, respectively. Starch digestibility reported by Zanton and Heinrichs (2009) was similar $(95.56 \pm 1.11 \%)$ to that observed for the HS group when similar starch and $\mathrm{N}$ intakes were noted for dairy heifers of approximately the same age and $\mathrm{BW}$ as in the present experiment. 
Table 2. Feed intake of dairy heifers fed low starch (LS) or high starch (HS) diets with increasing daily yeast culture (YC) dose

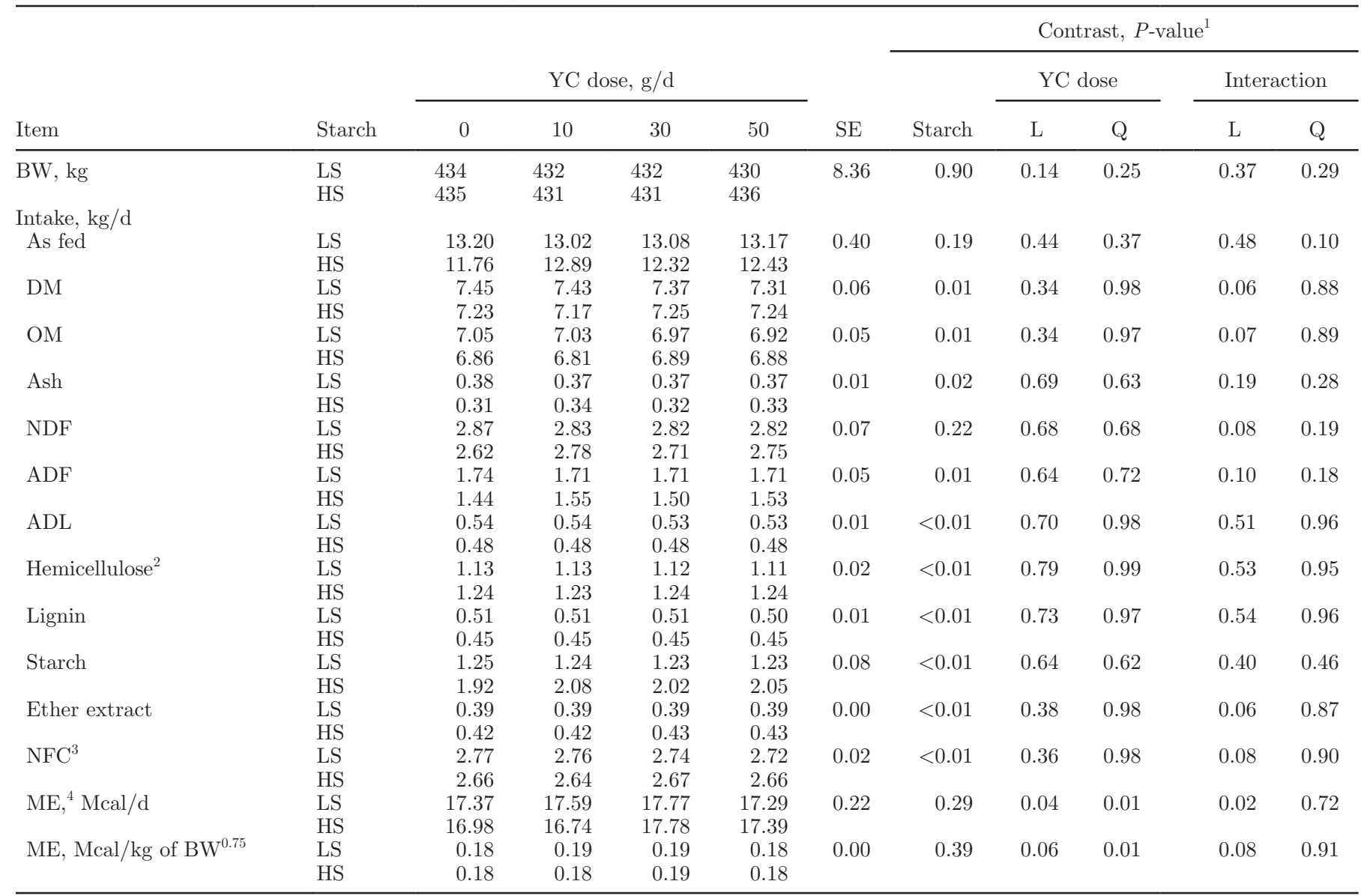

${ }^{1} \mathrm{~L}=$ linear; $\mathrm{Q}=$ quadratic.

${ }^{2}$ Hemicellulose $=$ NDF - ADF .

${ }^{3}$ Calculated from ingredients: $\mathrm{NFC}=100-(\mathrm{NDF}+\mathrm{CP}+$ ether extract + ash $)$.

${ }^{4}$ Calculated as digestible $\mathrm{OM} \times 0.82 \times 4.409$.

Total-tract AD of cellulose and ash was not affected by $\mathrm{YC}$ supplementation. Increasing $\mathrm{YC}$ daily dose increased AD of DM $(P \leq 0.01)$, OM $(P<0.01)$, NDF $(P=0.04)$, and $\operatorname{ADF}(P \leq 0.05)$ quadratically regardless of dietary starch concentration. Total-tract AD of hemicellulose tended to increase quadratically $(P \leq$ $0.10)$ with increasing $\mathrm{YC}$ daily dose, whereas total-tract $\mathrm{AD}$ of starch tended to decrease linearly $(P<0.07)$ with increasing YC daily dose in both LS and HS diets. Digestibility of DM, OM, NDF, and ADF increased with $10 \mathrm{~g} / \mathrm{d} \mathrm{YC}$ and peaked at $30 \mathrm{~g} / \mathrm{d}$. This pattern was also observed for hemicellulose but not for cellulose digestion, suggesting that $\mathrm{YC}$ had a larger effect on hemicellulose degradation. In a similar manner, Yoon and Stern (1996) observed higher hemicellulose digestibility when lactating cows were fed a 35\% corn silage and $15 \%$ grass hay diet with a YC product containing no live yeast cells and attributed this effect to increased numbers and proportion of cellulolytic microorganisms.
Yoon and Stern (1996) reported no effects of YC on ADF digestibility, whereas YC increased ADF digestion. In the present study, cellulose digestion did not attain statistical significance because of the high standard error observed for this parameter. Effects of YC on total-tract $\mathrm{AD}$ have been variable and diet dependent (Desnoyers et al., 2009), although to our knowledge, no experiment has assessed YC dose response to precision feeding of different dietary starch concentrations. The effects of YC observed in the present experiment were consistent with results from a previous experiment in which Lascano et al. (2009a) observed increased DM, $\mathrm{OM}$, and NDF AD in heifers fed high or low concentrate diets with $\mathrm{YC}$ addition at $1 \mathrm{~g} / \mathrm{kg}$ of feed on an as-fed basis (approximately $13 \mathrm{~g} / \mathrm{d}$ ).

In the present experiment, dietary starch did not affect $\mathrm{OM}$ digestibility, and mixed regression analysis showed that digested NDF $(x)$ modulated OM digestibility $(y)$ quadratically: $y=83.76( \pm 5.50 ; P \leq 0.01)$ 
Table 3. Nutrient digestibility of dairy heifers fed low starch (LS) or high starch (HS) diets with increasing yeast culture (YC) dose

\begin{tabular}{|c|c|c|c|c|c|c|c|c|c|c|c|}
\hline \multirow[b]{3}{*}{ Digestibility, \% } & \multirow[b]{3}{*}{ Starch } & & & & & \multirow[b]{3}{*}{$\mathrm{SE}$} & \multicolumn{5}{|c|}{ Contrast, $P$-value ${ }^{1}$} \\
\hline & & \multicolumn{4}{|c|}{$\mathrm{YC}$ dose, $\mathrm{g} / \mathrm{d}$} & & \multirow[b]{2}{*}{ Starch } & \multicolumn{2}{|c|}{ YC dose } & \multicolumn{2}{|c|}{ Interaction } \\
\hline & & 0 & 10 & 30 & 50 & & & $\mathrm{~L}$ & $\mathrm{Q}$ & $\mathrm{L}$ & $\mathrm{Q}$ \\
\hline \multirow[t]{2}{*}{$\mathrm{DM}$} & LS & 64.47 & 65.39 & 66.57 & 65.23 & \multirow[t]{2}{*}{0.63} & \multirow[t]{2}{*}{0.81} & \multirow[t]{2}{*}{0.01} & \multirow[t]{2}{*}{0.01} & \multirow[t]{2}{*}{0.14} & \multirow[t]{2}{*}{0.87} \\
\hline & HS & 64.45 & 64.06 & 67.53 & 66.16 & & & & & & \\
\hline $\mathrm{OM}$ & LS & 68.2 & 69.17 & 70.54 & 69.15 & 0.81 & 0.97 & 0.09 & 0.01 & 0.21 & 0.67 \\
\hline NDF & HS & 50.86 & 52.99 & 57.39 & 53.73 & 2.13 & 0.25 & 0.92 & 0.04 & 0.13 & 0.58 \\
\hline \multirow[t]{2}{*}{$\mathrm{ADF}$} & LS & 51.51 & 51.35 & 54.08 & 51.82 & \multirow[t]{2}{*}{1.78} & \multirow[t]{2}{*}{0.02} & \multirow[t]{2}{*}{0.15} & \multirow[t]{2}{*}{0.05} & 0.4 & 0.42 \\
\hline & HS & 46.42 & 47.07 & 53.3 & 48.99 & & & & & & \\
\hline Hemicellulose $^{2}$ & LS & 48.11 & 54.07 & 50.54 & 42.78 & 4.14 & 0.07 & 0.35 & 0.10 & 0.09 & 0.23 \\
\hline & HS & 59.79 & 56.25 & 62.63 & 59.66 & & & & & & \\
\hline Cellulose $^{3}$ & LS & 63.69 & 61.97 & 64.5 & 60.89 & 2.73 & 0.01 & 0.73 & 0.4 & 0.32 & 0.88 \\
\hline & HS & 56.07 & 53.5 & 60.8 & 57.27 & & & & & & \\
\hline
\end{tabular}

${ }^{1} \mathrm{~L}=$ linear; $\mathrm{Q}=$ quadratic.

${ }^{2}$ Hemicellulose $=$ NDF - ADF.

${ }^{3}$ Cellulose $=\mathrm{ADF}-\mathrm{ADL}$.

$x-24.60( \pm 3.88 ; P \leq 0.01) x^{2}$, with an intercept not differing from zero. This suggests that the YC effect on DM and OM digestibility was primarily due to its effect on the fiber portion of the diet. Effects of YC on starch digestion differed greatly from those observed for dietary fiber. Starch digestion tended to decrease linearly $(P=0.07)$ with increasing $\mathrm{YC}$ daily dose. This response was also analyzed through regression analysis, and functions were not different between starch treatments $(P=0.20)$ but the slope component differed with YC dose $(x ; P=0.02)$. The response for HS was as follows: starch digestibility $(y)=95.91( \pm 1.75)-0.047$ $( \pm 0.045) x$, whereas the response for LS was $y=95.59$ $( \pm 1.70)-0.201( \pm 0.04) x$. These results indicate that YC decreased starch digestibility in LS diet, whereas it remained largely unchanged in the HS diet (Figure 1). Both Jouany et al. (1998) and Mathieu et al. (1996) observed that digestion of starch was delayed by an increased number of protozoa when YC was added to sheep diets. Protozoa can engulf starch granules, thus decreasing their availability and digestion (Enjalbert et al., 1999). These observations suggest that YC may trigger a response in starch digestion, possibly mediated by protozoa, depending on the dietary starch concentration, and thus explaining the different results reported in the literature when different diets are fed. Protozoa numbers were lower in the YC-supplemented diet than in the control diet when high starch concentrations were fed (Garcia et al., 2000), and the opposite occurred in animals fed low starch concentrations (Plata et al., 1994). Miranda et al. (1996) reported a decrease in entodiniomorph numbers when $\mathrm{YC}$ was added to $37 \%$ NDF diets but no effects on rumen starch digestion. It seems that protozoa are influenced by YC dose and that this effect modulates starch digestion in LS diets. Interactions between dietary starch concentration and YC dose were only significant for hemicelluloses $(P=0.09)$ and $\mathrm{N}$ digestion $(P=0.10)$ in the current study. These observations are congruent with results observed in an earlier study with dairy heifers under similar precision feeding conditions (Lascano et al., 2009b). Regression analysis revealed a significant quadratic increase in hemicellulose digestion in LS-fed heifers, whereas no effect was detected in the HS group (Figure 1). Nitrogen intake was not different between dietary starch concentrations, but $\mathrm{AD}$ was greater for LS-fed heifers (66.85 vs. $61.69 \pm 1.13 ; P=0.02$ ). Thus, HS-fed heifers excreted more fecal N (Table 4). This digestibility coefficient is similar (around $60 \%$ ) to that observed when diets with differing forage to concentrate ratios were precision-fed to dairy heifers (Lascano and Heinrichs, 2011). Most studies report no difference or an improvement in $\mathrm{N} \mathrm{AD}$, similar to the improvement reported here when inclusion levels of CPP were intermediate (Schaibly and Wing, 1974).

We observed a quadratic decrease $(P=0.01)$ in fecal $\mathrm{N}$ excretion as dietary $\mathrm{YC}$ daily dose increased, but urinary $\mathrm{N}$ excretion was similar across $\mathrm{YC}$ doses. This resulted in no effects of $\mathrm{YC}$ on total $\mathrm{N}$ excreted or retained on a grams per day basis or expressed as a percentage of $\mathrm{N}$ intake. However, total-tract $\mathrm{N}$ AD $(P$ $=0.01$ ) and $\mathrm{N}$ retained expressed as a percentage of 

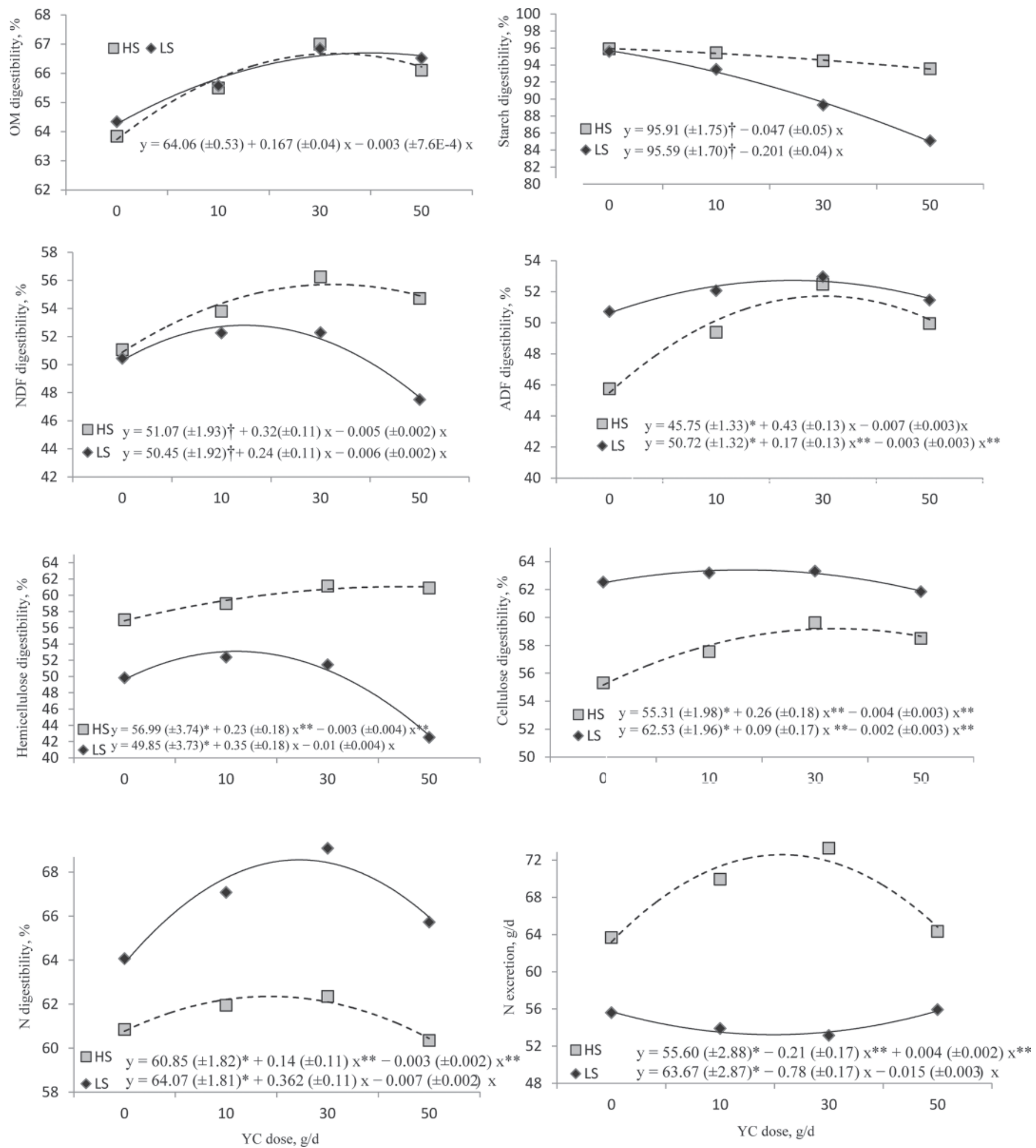

Figure 1. Dose response of yeast culture (YC, x-axis; 0, 10, 30 or $50 \mathrm{~g} / \mathrm{d}$ ) in low (LS) or high (HS) dietary starch concentration on OM, starch, NDF, ADF, hemicellulose, cellulose, and N digestibility, and fecal N excretion (y-axis, g/d). Parenthetical values associated with the equation are standard errors. For some parameters, lines were not significantly different $(P>0.10)$, individual coefficients were not different $(P>0.10)$, and a common equation represented both dietary starch treatments. Individual equations are presented in the respective figures. $\dagger$ Functions were not different between treatments, but the slope component differed upon YC dose $(\mathrm{x})$; ${ }^{*}$ functions were different between treatments, but the slope component was not dependent upon $\mathrm{YC}$ dose $\left(\mathrm{x}^{* *}\right)$. 
Table 4. Digestibility, excretion, and retention of nitrogen in dairy heifers fed low starch (LS) or high starch (HS) diets with increasing yeast culture (YC) dose

\begin{tabular}{|c|c|c|c|c|c|c|c|c|c|c|c|}
\hline \multirow{2}{*}{ Item } & \multirow{2}{*}{ Starch } & & & & & \multirow{2}{*}{$\mathrm{SE}$} & \multicolumn{5}{|c|}{ Contrast, $P$-value ${ }^{1}$} \\
\hline & & \multicolumn{4}{|c|}{ YC dose, $\mathrm{g} / \mathrm{d}$} & & Starch & \multicolumn{2}{|c|}{ YC dose } & \multicolumn{2}{|c|}{ Interaction } \\
\hline \multirow[t]{2}{*}{ Digestibility, \% } & LS & 65.0 & 68.3 & 69.1 & 64.9 & 1.49 & 0.02 & 0.22 & 0.01 & 0.13 & 0.10 \\
\hline & HS & 61.6 & 57.6 & 65.3 & 62.3 & & & & & & \\
\hline Intake, $\mathrm{g} / \mathrm{d}$ & LS & 163.7 & 163.8 & 162.8 & 161.6 & 3.57 & 0.58 & 0.69 & 0.79 & 0.11 & 0.78 \\
\hline Fecal N, g/d & HS & 59.7 & 66.2 & 54.3 & 58.9 & & & & & & \\
\hline \multirow[t]{2}{*}{ Urine $\mathrm{N}, \mathrm{g} / \mathrm{d}$} & LS & 66.3 & 70.0 & 67.5 & 62.4 & 11.38 & 0.27 & 0.15 & 0.24 & 0.27 & 0.65 \\
\hline & HS & 55.6 & 66.8 & 50.8 & 65.6 & & & & & & \\
\hline \multirow{2}{*}{ Total excreted N, g/d } & LS & 116.5 & 120.7 & 118.6 & 143.4 & 12.78 & 0.41 & 0.14 & 0.34 & 0.38 & 0.68 \\
\hline & HS & 108.8 & 117.9 & 107.0 & 120.3 & & & & & & \\
\hline \multirow{2}{*}{ Retained N, g/d } & LS & 39.8 & 41.7 & 44.9 & 42.4 & 14.42 & 0.55 & 0.35 & 0.21 & 0.23 & 0.44 \\
\hline & HS & 40.1 & 21.3 & 51.2 & 31.6 & & & & & & \\
\hline
\end{tabular}

${ }^{1} \mathrm{~L}=$ linear; $\mathrm{Q}=$ quadratic.

${ }^{2}$ Retained N, \% digested $=$ percentage of $\mathrm{N}$ digested and grams of $\mathrm{N}$ retained.

$\mathrm{N}$ digested $(P=0.09)$ increased quadratically with increasing YC daily dose, reaching a maximum at $30 \mathrm{~g} / \mathrm{d}$ $\mathrm{YC}$ addition. Because we found a significant quadratic interaction $(P=0.10)$ between starch concentration and $\mathrm{YC}$ dose for $\mathrm{N}$ digestion, we analyzed this response through regression. Digestion of $\mathrm{N}$ increased quadratically as YC dose increased in LS-fed heifers, whereas no effects were detected for the HS-fed group. Response functions were different between starch treatments, and the slope component depended upon YC dose $(P$ $<0.01$ ). These results indicate that $\mathrm{YC}$ increased $\mathrm{N}$ digestion to a greater extent in the LS diet, whereas it did not affect $\mathrm{N}$ AD in HS, a finding corroborated by the similar inverse quadratic effect on fecal $\mathrm{N}$ excretion (Figure 1). The increased availability of propionate usually observed in HS diets can increase incorporation of RDP into microbial protein, increasing efficiency of N utilization (Sommerfeldt and Lyon, 1988). This may explain the quadratic response observed for $\mathrm{N}$ digestibility, which is consistent with DM and OM digestibility. In a previous study using heifers of similar age, $\mathrm{N}$ digestion was numerically greater when $\mathrm{YC}$ was added at $13 \mathrm{~g} / \mathrm{d}$ (Lascano et al., 2009b).

\section{Nutrient Excretion}

Nutrient excretion data are presented in Table 5. All excretion variables measured and water balance were similar for both dietary starch concentrations $(P>$ $0.10)$. These values are similar to those reported by Zanton and Heinrichs (2009) and Lascano et al. (2009b) for heifers with similar nutrient intakes and BW fed 25 and $20 \%$ concentrate, respectively, in a controlled environment facility.

Increasing YC daily dose decreased fecal DM output quadratically $(P \leq 0.01)$ with $30 \mathrm{~g} / \mathrm{d}$ of $\mathrm{YC}$ resulting in the lowest output. Other nutrient outputs were not influenced by YC. The quadratic reduction in dry fecal output reflected the quadratic increase observed in DM and OM digestion. This reduction in fecal DM output is in agreement with a previous study in which YC also reduced dry fecal output without changing urine output (Lascano et al., 2009b). Total water excreted tended to increase linearly $(P=0.09)$ with YC dose in both dietary starch treatments and was correlated to urine output in the present experiment $(\mathrm{r}=0.89)$. A significant quadratic interaction $(P=0.10)$ between dietary starch concentration and YC dose was observed for wet fecal output. Increasing the $\mathrm{YC}$ daily dose reduced wet fecal output in LS-fed heifers and increased it in HS-fed heifers. This response was caused mainly by a similar quadratic interaction effect $(P \leq 0.10)$ in fecal water excretion. Fecal water excretion was highly correlated with NDF excretion in the present study (r $=0.96$ ) as well as in a previous study by Zanton and Heinrichs (2009).

Temperature and relative humidity during the experiment averaged $24.6 \pm 1.5^{\circ} \mathrm{C}$ and $73.8 \pm 3.1 \%$, respectively. Voluntary and total water intakes were similar among dietary starch concentrations (Table 6). Total water excretion was $59.1 \%$ of total water intake in the present experiment, with $32 \pm 3 \%$ of total water intake 
Table 5. Excretion parameters of dairy heifers fed low starch (LS) or high starch (HS) diets with increasing daily yeast culture (YC) dose

\begin{tabular}{|c|c|c|c|c|c|c|c|c|c|c|c|}
\hline \multirow[b]{2}{*}{ Item, $\mathrm{kg} / \mathrm{d}$} & \multirow[b]{2}{*}{ Starch } & \multicolumn{4}{|c|}{ YC dose, $\mathrm{g} / \mathrm{d}$} & \multirow[b]{2}{*}{$\mathrm{SE}$} & \multicolumn{5}{|c|}{ Contrast, $P$-value ${ }^{1}$} \\
\hline & & 0 & 10 & 30 & 50 & & Starch & $\mathrm{L}$ & $\mathrm{Q}$ & $\mathrm{L}$ & $\mathrm{Q}$ \\
\hline \multirow[t]{2}{*}{ Wet feces } & LS & 14.00 & 13.27 & 13.41 & 13.80 & 0.81 & 0.23 & 0.82 & 0.68 & 0.75 & 0.10 \\
\hline & HS & 11.84 & 12.42 & 12.28 & 12.17 & & & & & & \\
\hline Dry feces & LS & 2.29 & 2.18 & 2.08 & 2.16 & 0.10 & 0.33 & 0.01 & 0.00 & 0.36 & 0.31 \\
\hline Fecal water ${ }^{2}$ & HS & 9.81 & 10.28 & 10.37 & 10.12 & & & & & & \\
\hline \multirow[t]{2}{*}{ Urine } & LS & 6.44 & 7.27 & 7.31 & 8.56 & 1.69 & 0.59 & 0.17 & 0.58 & 0.29 & 0.78 \\
\hline & HS & 6.10 & 6.24 & 5.66 & 6.55 & & & & & & \\
\hline \multirow[t]{2}{*}{ Manure } & LS & 20.52 & 20.59 & 20.75 & 22.28 & 1.93 & 0.34 & 0.11 & 0.41 & 0.35 & 0.64 \\
\hline & HS & 17.93 & 18.62 & 17.93 & 18.73 & & & & & & \\
\hline Total excreted & LS & 18.22 & 18.40 & 18.67 & 20.14 & 1.89 & 0.35 & 0.09 & 0.53 & 0.33 & 0.68 \\
\hline
\end{tabular}

${ }^{1} \mathrm{~L}=$ linear; $\mathrm{Q}=$ quadratic.

${ }^{2}$ Weight lost on drying at $55^{\circ} \mathrm{C}$.

excreted in feces and $24 \pm 2 \%$ excreted in urine. Excretion of water in feces and urine occurred in a 62:38 ratio (diet NDF was $39 \%$ of DM). When dairy heifers housed under similar conditions were fed a diet containing $30 \%$ $\mathrm{NDF}$ on a DM basis, fecal water to urine ratio was 39:61 (Lascano et al., 2010). These results are in agreement with other observations that show water excretion shifting toward more fecal water as the amount of NDF in dairy heifer diets increases (Lascano et al., 2012). A significant quadratic interaction $(P=0.10)$ between dietary starch concentration and $\mathrm{YC}$ dose was also observed for voluntary and total water intakes. Voluntary and total water intakes decreased quadratically $(P \leq$ $0.10)$ in LS-fed heifers and increased quadratically in HS-fed heifers. The lowest water intake was achieved with $10 \mathrm{~g} / \mathrm{d} \mathrm{YC}$ in the LS diet, and the greatest water intake was achieved with $30 \mathrm{~g} / \mathrm{d} \mathrm{YC}$ in the HS diet. These observations are intriguing; however, no physiological explanation is available at this time.

\section{Blood Metabolites}

Blood metabolite observations are presented in Table 7. Blood metabolites were measured $2 \mathrm{~h}$ before and after feeding, and a significant time effect was observed for all blood metabolites measured $(P \leq 0.01)$. Dietary starch concentration did not affect glucose, triglycerides, creatinine, or lactate concentrations. However, the HS diet produced greater plasma urea nitrogen $(P \leq 0.01)$ concentrations than the LS diet. Similar results were reported by Herrera-Saldana and Huber (1989) when lactating cows were fed differing starch concentrations, and this effect was attributed to a more rapid degradation rate of barley protein. Other researchers observed greater protein degradation to ammonia- $\mathrm{N}$ with higher numbers of protozoa, and protozoa numbers have been suggested to be higher in HS diets (Slyter et al., 1971; Dennis et al., 1983).

Increasing YC dose tended to increase glucose concentration quadratically $(P \leq 0.10)$ but had no effect on the other blood metabolites measured. Interestingly, glucose concentrations in LS heifers increased quadratically, peaking at $30 \mathrm{~g} / \mathrm{d}$, which was not the case for the HS group, in which glucose concentrations were constant across the different YC doses. This observation is consistent with the increased propionate concentration in the rumen (Lascano et al., 2009b) for both dietary treatments when $\mathrm{YC}$ dose was increased. Oba and Allen (2003) observed increased plasma glucose concentrations with increasing intraruminal infusion of propionate to early lactation dairy cows. Dietary starch concentration and $\mathrm{YC}$ dose interacted for triglyceride concentrations, decreasing quadratically $(P=0.05)$ in the LS group and increasing in the HS group with both the lowest and highest values at $10 \mathrm{~g} / \mathrm{d}$ YC, respectively. The increased level of glucose was likely due to increased nutrient utilization that resulted in increased $\mathrm{DM}$ and $\mathrm{OM} \mathrm{AD}$. These results reflect the diet dependency of the mode of action of YC. Other experiments have reported increased triglyceride concentrations with YC supplementation and suggested preferential fat mobilization with the use of YC when diets contained high levels of ground corn (Giger-Reverdin et al., 1996).

Propionate level for LS diets has been reported to be significantly lower compared with those for HS diets (Leiva et al., 2000), suggesting that the effect of YC on glucose metabolism is diet dependent. In contrast, increases in serum triglycerides have been attributed to greater ruminal and liver acetate concentrations (Galip, 
Table 6. Water intake and proportion excreted of dairy heifers fed low starch (LS) or high starch (HS) diets with increasing daily yeast culture (YC) dose

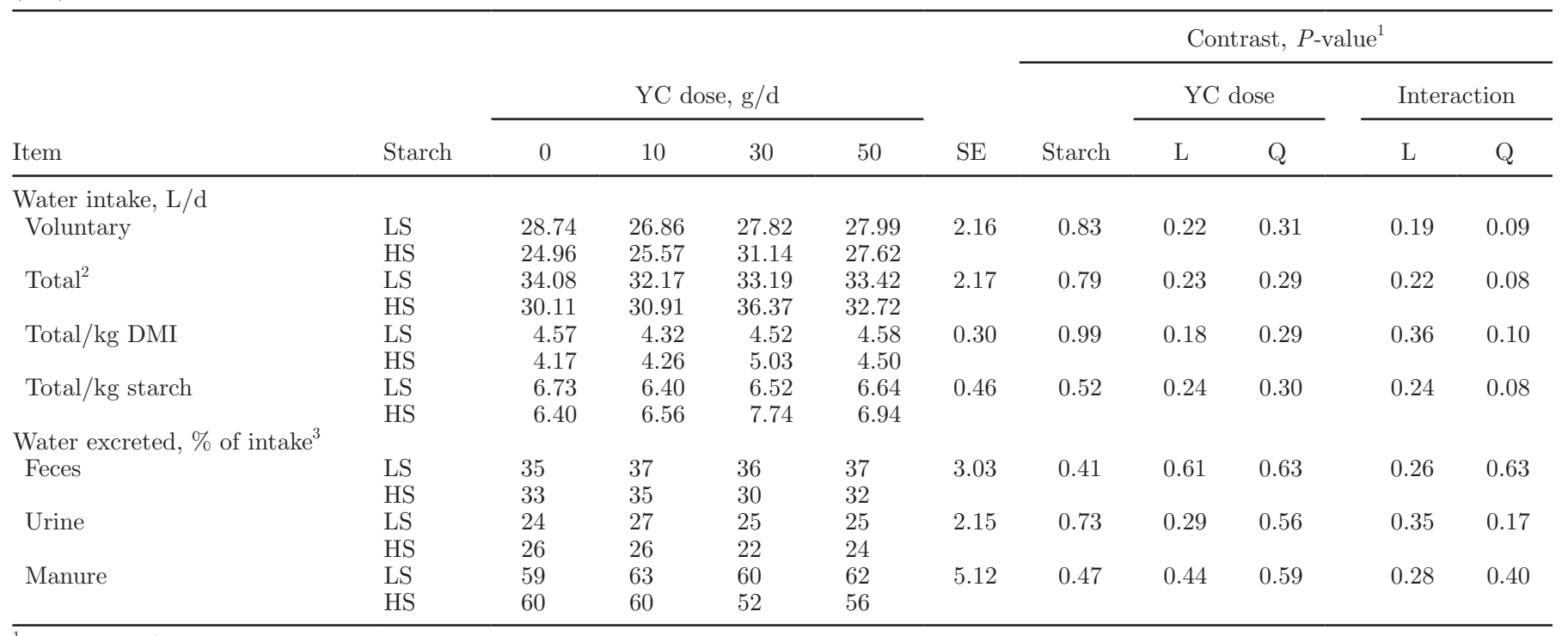

${ }^{1} \mathrm{~L}=$ linear; $\mathrm{Q}=$ quadratic.

${ }^{2}$ Total water intake $=$ voluntary water intake + feed water.

${ }^{3}$ Consumption is total water intake, and excretion includes fecal water calculated as weight lost on drying at $55^{\circ} \mathrm{C}$ and total weight of urine output.

2006). No interactions were observed for plasma urea $\mathrm{N}$, creatinine, or lactate.

\section{CONCLUSIONS}

In summary, DM and OM AD were not different between HS and LS diets, but ADF digestibility decreased in the HS diet because of a reduction in cellulose digestion. In contrast, hemicellulose digestion tended to be higher in the HS diet, resulting in no differences in NDF digestibility. Apparent $\mathrm{N}$ digestibility was greater in the LS group, in agreement with other experiments where intermediate levels of ground corn and corn silage were replaced by CPP. Concurrent lower plasma urea $\mathrm{N}$ concentrations in the LS group support results observed for $\mathrm{N}$ digestibility. These results support the feasibility of using CPP to replace corn in the diet of dairy heifers. Increasing YC dose increased DM, OM, $\mathrm{NDF}$, and ADF AD quadratically and tended to increase hemicellulose AD quadratically. Digestibility of $\mathrm{N}$ increased quadratically as $\mathrm{YC}$ dose increased in LS-fed heifers, whereas no effect was detected for the HS group. These results indicate that YC increased $\mathrm{N}$ digestibility to a higher extent in LS diet, whereas it

Table 7. Blood metabolites of dairy heifers fed low starch (LS) or high starch (HS) diets with increasing daily yeast culture (YC) dose

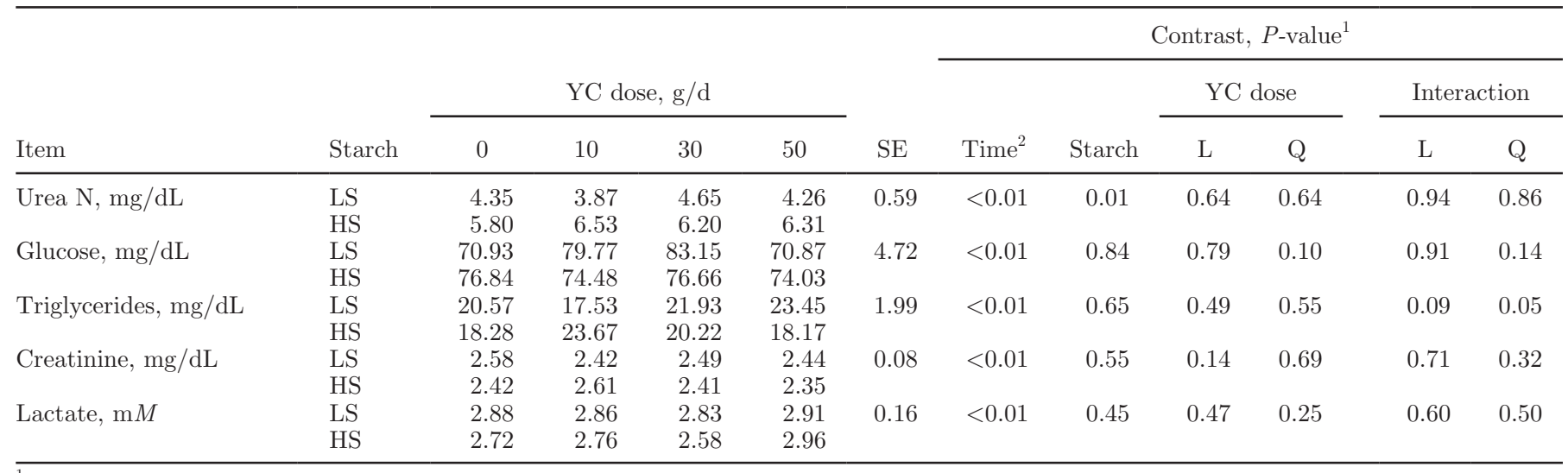

${ }^{1} \mathrm{~L}=$ linear; $\mathrm{Q}=$ quadratic.

${ }^{2}$ Blood samples were taken $2 \mathrm{~h}$ before and after feeding during the collection period. 
was not affected in the HS diet. Dose of YC influenced glucose and triglyceride concentrations differently according to starch concentration of the diet. Increasing $\mathrm{YC}$ dose had a quadratic effect on serum glucose concentration and had a tendency to interact with starch concentration. For triglycerides, dietary starch concentration and YC daily dose interacted, decreasing quadratically in the LS group and increasing in the HS group. Addition of $\mathrm{YC}$ triggered a response starting at a daily dose of $10 \mathrm{~g} / \mathrm{d}$ and peaking at $30 \mathrm{~g} / \mathrm{d}$ for most items measured. Effects of $\mathrm{YC}$ on rumen fermentation profiles and bacterial populations will aid to clarify the responses observed in this study of digestion and blood metabolites.

\section{ACKNOWLEDGMENTS}

Appreciation is extended to M. R. Long for laboratory assistance, E. Bornatici, G. I. Zanton, F. X. Suarez-Mena, D. D. Maulfair, and D. Rico (all of Pennsylvania State University, University Park) for assistance with animals and data collection, and C. M. Jones (Craigsville, VA) for editorial assistance to complete this experiment partially funded by Alltech Inc. (Nicholasville, KY).

\section{REFERENCES}

AOAC. 2000. Official Methods of Analysis. 17th ed. Association of Official Analytical Chemists, Gaithersburg, MD.

Ariza, P., A. Bach, M. D. Stern, and M. B. Hall. 2001. Effects of carbohydrates from citrus pulp and hominy feed on microbial fermentation in continuous culture. J. Anim. Sci. 79:2713-2718.

Bampidis, V. A., and P. H. Robinson. 2006. Citrus by-products as ruminant feeds: A review. Anim. Feed Sci. Technol. 128:175-217.

Bueno, M. S., E. Ferrari, D. Bianchini, F. F. Leinz, and C. F. C. Rodrigues. 2002. Effect of replacing corn with dehydrated citrus pulp in diets of growing kids. Small Rumin. Res. 46:179-185.

Chen, X. B. 1989. Excretion of purine derivatives by sheep and cattle and its use for the estimation of absorbed microbial protein. PhD Thesis. University of Aberdeen, UK.

Dawson, K. A., K. A. Newman, and J. A. Boling. 1990. Effect of microbial supplements containing yeast and lactobacilli on roughagefed ruminal microbial activities. J. Anim. Sci. 68:3392-3398.

Dennis, S. M., M. J. Arambel, E. E. Bartley, and A. D. Dayton. 1983. Effect of energy concentration and source of nitrogen on numbers and types of rumen protozoa. J. Dairy Sci. 66:1248-1254.

Desnoyers, M., S. Giger-Reverdin, G. Bertin, C. Duvaux-Ponter, and D. Sauvant. 2009. Meta-analysis of the influence of Saccharomyces cerevisiae supplementation on ruminal parameters and milk production of ruminants. J. Dairy Sci. 92:1620-1632.

Enjalbert, F., J. E. Garret, R. Moncoulon, C. Bayourthe, and P. Chicoteau. 1999. Effect of yeast culture (Saccharomyces cerevisiae) on ruminal digestion in non-lactating dairy cows. Anim. Feed Sci. Technol. 76:195-206.

Fegeros, K., G. Zervas, S. Stamouli, and E. Apostolaki. 1995. Nutritive value of dried citrus ulp and its effect on milk yield and milk composition of lactating ewes. J. Dairy Sci. 78:1116-1121.

Galip, N. 2006. Effect of supplemental yeast culture and sodium bicarbonate on ruminal fermentation and blood variables in rams. J. Anim. Physiol. Anim. Nutr. (Berl.) 90:446-452.
Garcia, C. C. G., M. G. D. Mendoza, M. S. Gonzalez, P. M. Cobos, C. M. E. Ortega, and L. R. Ramirez. 2000. Effect of a yeast culture (Saccharomyces cerevisiae) and monensin on ruminal fermentation and digestion in sheep. Anim. Feed Sci. Technol. 83:165-170.

Giger-Reverdin, S., N. Bezault, D. Sauvant, and G. Bertin. 1996. Effects of a probiotic yeast in lactating ruminants: Interaction with dietary nitrogen level. Anim. Feed Sci. Technol. 63:149-162.

Hall, M. B., and C. Herejk. 2001. Differences in yields of microbial crude protein from in vitro fermentation of carbohydrates. J. Dairy Sci. 84:2486-2493.

Herrera-Saldana, R., and J. T. Huber. 1989. Influence of varying protein and starch degradabilities on performance of lactating cows. J. Dairy Sci. 72:1477-1483.

Hoffman, P. C., C. R. Simson, and M. Wattiaux. 2007. Limit feeding of gravid Holstein heifers: Effect on growth, manure nutrient excretion, and subsequent early lactation performance. J. Dairy Sci. 90:946-954.

Huntington, G. B., and P. J. Reynolds. 1983. Net volatile fatty acid absorption in nonlactating Holstein cows. J. Dairy Sci. 66:86-92.

Jouany, J. P., F. Mathieu, J. Senaud, J. Bohatier, G. Bertin, and M. Mercier. 1998. The effect of Saccharomyces cerevisiae and Aspergillus oryzae on the digestion of the cell wall fraction of a mixed diet in defaunated and refaunated sheep rumen. Reprod. Nutr. Dev. $38: 401-416$

Kenward, M. G., and J. H. Roger. 1997. Small sample inference for fixed effects from restricted maximum likelihood. Biometrics 53:983-997.

Lascano, G. J., and A. J. Heinrichs. 2009. Rumen fermentation pattern of dairy heifers fed restricted amounts of low, medium, and high concentrate diets without and with yeast culture. Livest. Sci. 124:48-57.

Lascano, G. J., and A. J. Heinrichs. 2011. Effects of feeding different levels of dietary fiber through the addition of corn stover on nutrient utilization of dairy heifers precision-fed high and low concentrate diets. J. Dairy Sci. 94:3025-3036.

Lascano, G. J., M. Velez, J. M. Tricarico, and A. J. Heinrichs. 2012. Short communication: Nutrient utilization of fresh sugarcanebased diets with slow-release nonprotein nitrogen addition for control-fed dairy heifers. J. Dairy Sci. 95:370-376.

Lascano, G. J., G. I. Zanton, and A. J. Heinrichs. 2009a. Concentrate levels and Saccharomyces cerevisiae affect rumen fluid-associated bacteria numbers in dairy heifers. Livest. Sci. 126:189-194.

Lascano, G. J., G. I. Zanton, A. J. Heinrichs, and W. P. Weiss. 2010. Technical note: A noninvasive urine collection device for female cattle: Modification of the urine cup collection method. J. Dairy Sci. 93:2691-2694

Lascano, G. J., G. I. Zanton, M. L. Moody, P. A. Topper, E. F. Wheeler, and A. J. Heinrichs. 2008. Short communication: Effect of changing the ratio of forage to concentrate on ammonia emissions by dairy heifers. J. Dairy Sci. 91:4301-4306.

Lascano, G. J., G. I. Zanton, F. X. Suarez-Mena, and A. J. Heinrichs. 2009b. Effect of limit feeding high- and low-concentrate diets with Saccharomyces cerevisiae on digestibility and on dairy heifer growth and first-lactation performance. J. Dairy Sci. 92:51005110

Leiva, E., M. B. Hall, and H. H. Van Horn. 2000. Performance of dairy cattle fed citrus pulp or corn products as sources of neutral detergent-soluble carbohydrates. J. Dairy Sci. 83:2866-2875.

Marden, J. P., C. Julien, V. Monteils, E. Auclair, R. Moncoulon, and C. Bayourthe. 2008. How does live yeast differ from sodium bicarbonate to stabilize ruminal $\mathrm{pH}$ in high-yielding dairy cows? J. Dairy Sci. 91:3528-3535.

Mathieu, F., J. P. Jouany, J. Senaud, J. Bohatier, G. Bertin, and M. Mercier. 1996. The effect of Saccharomyces cerevisiae and Aspergillus oryzae on fermentations in the rumen of faunated and defaunated sheep; protozoal and probiotic interactions. Reprod. Nutr. Dev. 36:271-287.

Miranda, R. L. A., M. G. D. Mendoza, J. R. Barcenagama, M. S. S. Gonzalez, R. Ferrara, C. M. E. Ortega, and P. M. A. Cobos. 1996. Effect of Saccharomyces cerevisiae or Aspergillus oryzae cultures 
and NDF level on parameters of ruminal fermentation. Anim. Feed Sci. Technol. 63:289-296.

Miron, J., E. Yosef, D. Ben-Ghedalia, L. E. Chase, D. E. Bauman, and R. Solomon. 2002. Digestibility by dairy cows of monosaccharide constituents in total mixed rations containing citrus pulp. J. Dairy Sci. 85:89-94.

Moody, M. L., G. I. Zanton, J. M. Daubert, and A. J. Heinrichs. 2007. Nutrient utilization of differing forage to concentrate ratios by growing Holstein heifers. J. Dairy Sci. 90:5580-5586.

National Research Council. 2001. Nutrient Requirements of Dairy Cattle. 7th rev. ed. Natl. Acad. Press, Washington, DC.

Nocek, J. E. 1997. Bovine acidosis: Implications on laminitis. J. Dairy Sci. 80:1005-1028.

Nocek, J. E., W. P. Kautz, J. A. Z. Leedle, and J. G. Allman. 2002. Ruminal supplementation of direct-fed microbials on diurnal $\mathrm{pH}$ variation and in situ digestion in dairy cattle. J. Dairy Sci. $85: 429-433$.

Oba, M., and M. S. Allen. 2003. Extent of hypophagia caused by propionate infusion is related to plasma glucose concentration in lactating dairy cows. J. Nutr. 133:1105-1112.

Plata, F., G. D. Mendoza, J. R. Barcenagama, and S. Gonzalez. 1994. Effect of a yeast culture (Saccharomyces cerevisiae) on neutral detergent fiber digestion in steers fed oat straw based diets. Anim. Feed Sci. Technol. 49:203-210.

Sarwar, M., J. L. Firkins, and M. L. Eastridge. 1991. Effect of replacing neutral detergent fiber of forage with soyhulls and corn gluten feed for dairy heifers. J. Dairy Sci. 74:1006. (Abstr.)

Schaibly, G. E., and J. M. Wing. 1974. Effect of roughage concentrate ratio on digestibility and rumen fermentation of corn silage citrus pulp rations. J. Anim. Sci. 38:697-701.

Slyter, L. L., D. L. Kern, J. M. Weaver, R. R. Oltjen, and R. L. Wilson. 1971. Influence of starch and nitrogen sources on ruminal microorganisms of steers fed high fiber purified diets. J. Nutr. 101:847-853.
Sommerfeldt, J. L., and K. A. Lyon. 1988. Ration digestibilities and ruminal characteristics in steers fed chickpeas. J. Dairy Sci. 71:843-847.

Strobel, H. J., and J. B. Russell. 1986. Effect of $\mathrm{pH}$ and energy spilling on bacterial protein-synthesis by carbohydrate-limited cultures of mixed rumen bacteria. J. Dairy Sci. 69:2941-2947.

Titgemeyer, E. C., L. D. Bourquin, and G. C. Fahey. 1992. Disappearance of cell-wall monomeric components from fractions chemically isolated from alfalfa leaves and stems following insitu ruminal digestion. J. Food Agric. 58:451-463.

Van Soest, P. J. 1994. Nutritional Ecology of the Ruminant. 2nd ed. Comstock Publ., Ithaca, NY.

Van Soest, P. J., J. B. Robertson, and B. A. Lewis. 1991. Methods for dietary fiber, neutral detergent fiber, and nonstarch polysaccharides in relation to animal nutrition. J. Dairy Sci. 74:3583-3597.

Wiedmeier, R. D., M. J. Arambel, and J. L. Walters. 1987. Effect of yeast culture and Aspergillus oryzae fermentation extract on ruminal characteristics and nutrient digestibility. J. Dairy Sci. 70:2063-2068.

Yoon, I. K., and M. D. Stern. 1996. Effects of Saccharomyces cerevisiae and Aspergillus oryzae cultures on ruminal fermentation in dairy cows. J. Dairy Sci. 79:411-417.

Zanton, G. I., and A. J. Heinrichs. 2007. The effects of controlled feeding of a high-forage or high-concentrate ration on heifer growth and first-lactation milk production. J. Dairy Sci. 90:3388-3396.

Zanton, G. I., and A. J. Heinrichs. 2009. Digestion and nitrogen utilization in dairy heifers limit-fed a low or high forage ration at four levels of nitrogen intake. J. Dairy Sci. 92:2078-2094.

Zanton, G. I., and J. A. Heinrichs. 2010. Review: Limit-feeding with altered forage-to-concentrate levels in dairy heifer diets. Prof. Anim. Sci. 25:393-403. 